University of Nebraska - Lincoln

DigitalCommons@University of Nebraska - Lincoln

Faculty Publications, Department of Child, Youth, and Family Studies

2022

\title{
A qualitative comparison of parent and childcare provider perceptions of communication and family engagement in children's healthy eating and physical activity
}

Danae Dinkel

Maggie Rasmussen

John P. Rech

Kailey Snyder

Dipti Dev

Follow this and additional works at: https://digitalcommons.unl.edu/famconfacpub

Part of the Developmental Psychology Commons, Family, Life Course, and Society Commons, Other Psychology Commons, and the Other Sociology Commons

This Article is brought to you for free and open access by the Child, Youth, and Family Studies, Department of at DigitalCommons@University of Nebraska - Lincoln. It has been accepted for inclusion in Faculty Publications, Department of Child, Youth, and Family Studies by an authorized administrator of DigitalCommons@University of Nebraska - Lincoln. 


\title{
A qualitative comparison of parent and childcare provider perceptions of communication and family engagement in children's healthy eating and physical activity
}

\author{
Danae Dinkel, ${ }^{1}$ Maggie Rasmussen, ${ }^{1}$ John P. Rech, ${ }^{1}$ \\ Kailey Snyder, ${ }^{2}$ and Dipti A. Dev ${ }^{3}$

\footnotetext{
1 School of Health and Kinesiology, University of Nebraska at Omaha, Omaha, Nebraska, USA

2 Department of Physical Therapy, Creighton University, Omaha, Nebraska, USA

3 Department of Child, Youth, and Family Studies, University of Nebraska-

Lincoln, Lincoln, Nebraska, USA

Correspondence - Danae Dinkel, School of Health and Kinesiology, University of Nebraska at Omaha, 6001 Dodge St. H\&K 207Q, Omaha, NE 68182, USA. email

dmdinkel@unomaha.edu

ORCID Danae Dinkel https://orcid.org/oooo-0oo2-0262-4429
}

\begin{abstract}
Background: Parents and childcare providers play a substantial role in the development of health behaviors among the children they care for. In order to ensure the optimal growth and development of children, communication and family engagement in childcare is critical. Previous studies examining parent or provider perceptions about healthy eating or physical activity have explored these concepts individually and/or have only included only parents or providers. Therefore, the purpose
\end{abstract}

Published in Child Care, Health and Development 48 (2022), pp. 99-109.

DOI: $10.1111 /$ cch.12908

Copyright (C) 2021 John Wiley \& Sons Ltd. Used by permission.

Submitted 27 October 2020; revised 3 July 2021; accepted 11 August 2021; published

August 24, 2021. 
of this study was to compare childcare provider and parent perceptions of communication regarding healthy eating and physical activity as well as use of best practice strategies on family engagement for these topics.

Methods: Childcare providers $(n=12)$ in childcare centers or a family childcare home and a parent $(n=12)$ of a child they provide care for participated in a semistructured interview guided by the Social Ecological Model. Interviews were transcribed verbatim and uploaded to NVivo for data analysis. Data were analyzed using a directed content analysis. Three trained qualitative researchers developed a codebook and then compared responses between parents and providers.

Results: Similarities in provider and parent responses included agreement on healthy eating; influences on child development; parents being the most influential on children's healthy eating; how they identified physical activity opportunities; and the use of family engagement principles. Differences that arose included parents' roles in promoting children's physical activity; challenges for parents in promoting healthy eating and physical activity; and providers' encouragement of physical activity. Importantly, few parents mentioned providers were top influences on their child's healthy eating or physical activity. Providers also mentioned having difficult conversations with parents was challenging.

Conclusions: Future efforts are needed to (1) help parents understand the providers' role in the development of their child's health behaviors and (2) strengthen efforts to engage families in healthy behaviors outside of childcare facilities.

Keywords: childcare, family engagement, parents, providers

\section{Key Messages}

- Communication between providers and parents as well as engagement of parents is critical to the promotion of healthy eating and physical activity among children ages $0-5$.

- Previous studies have not included perceptions of both providers and parents about children ages $0-5$ healthy eating and physical activity.

- This study found several differences between providers and parents perceptions on aspects of children's healthy eating and physical activity.

- Few parents mentioned providers influenced their child's healthy eating and physical activity.

- Efforts are needed to help parents understand providers' role in child's development. 


\section{Introduction}

In the United States, $8.1 \%$ of children $0-2$ years old and $22.8 \%$ of children 2-5 years old are overweight or obese (Ogden et al., 2014). Being overweight or obese as a child increases one's risk for developing chronic health conditions such as diabetes and cardiovascular disease (World Health Organization, 2019). Healthy eating and physical activity are two behaviors that are widely recognized to positively influence childhood obesity prevention (Wolfenden et al., 2020). Parents are viewed as the primary influence on children's healthy eating and physical activity. Given that a majority of parents are the primary influence on their child's healthy eating and physical activity, and also given that a majority of children in the United States attend childcare, childcare providers also play a substantial role in the development of health behaviors among the children they care for (Child Care Licensing, 2020). In order to ensure the optimal growth and development of children, family engagement-a collaborative process in which positive relationships are built between parents and childcare providers-is critical (Head Start Early Childhood Learning \& Knowledge Center, n.d.).

One activity that can help support family engagement is communication (Dev et al., 2014). Previous studies have revealed the challenges to communication in childcare (Dev et al., 2017; Jayasuriya et al., 2016; Johnson et al., 2013; Mena et al., 2020). For example, one study focused on healthy eating in childcare found that parents felt staff did not provide enough time for conversations during child pickup time, and written reports lacked detail (Johnson et al., 2013). Specific to physical activity, almost $80 \%$ of preschoolers' parents reported no dialogue around the topic of outdoor play with their childcare provider, and greater than $50 \%$ of parents reported having no idea about how much time their child spent playing outdoors (Jayasuriya et al., 2016).

On the contrary, childcare providers report barriers in communicating with parents such as lack of face-to-face time with parents, parents prioritizing talking about food issues (e.g. food allergies) instead of nutrition in general, lack of training on communicating without conflict, and a lack of information retention from parents (Dev et al., 2017; Johnson et al., 2013; Mena et al., 2020). Ultimately, results suggest both parents and providers believe that communication with 
each other is important but often limited (Mena et al., 2020). Previous research though has primarily explored either the parents' or childcare providers' perceptions and focused only on healthy eating or physical activity (Dev et al., 2017; Johnson et al., 2013; Tandon et al., 2017). However, discrepancies in promotional practices are often uncovered between these two caregivers (Hennink-Kaminski et al., 2018; Luecking et al., 2020; Tandon et al., 2017). For example, parents in one study more often believed their child could get sick when playing outside in the cold compared with providers (Tandon et al., 2017). While in another study, providers thought communication was critical but parents had inconsistent feelings on whether it was important to communicate about children's healthy eating or physical activity behaviors (Luecking et al., 2020). Thus, additional studies are needed not only to collectively examine parent and provider perceptions (e.g. individuals own understanding of their experiences) on communication about healthy eating and physical activity but also to compare perceptions to see if consistency in perceptions on these topics within the same sample exist (Given, 2008).

Several organizations have developed principles for family engagement in childcare. One of the most widely recognized set of best practice principles for family engagement is from the National Association for the Education of Young Children (NAEYC; see Table 1), which includes principles such as partaking in two-way communication with parents and involving parents in program level decision making. However, little research has jointly examined and compared parent's perceptions of best practice strategies childcare providers may be using to engage parents in healthy eating and physical activity (National Association for the Education of Young Children [NAEYC], n.d.-a; Dwyer et al., 2008; Vandeweghe et al., 2016). Therefore, it is unknown to what extent providers are utilizing best practice principles and how parents are being involved within childcare for health promotion through practices described by the NAEYC. A better understanding of these perceptions and whether there is alignment between parents and providers could help to develop resources to increase family engagement and encourage greater consistency in health promotion practices between caregivers. Therefore, the purpose of this study was to compare childcare provider and parent perceptions of communication regarding healthy eating and physical activity as well as use of best practice strategies on family engagement for these topics. 


\section{Methods}

\subsection{Study design}

This qualitative comparison study was guided by a directed content analysis approach (Hsieh \& Shannon, 2005; Lindsay, 2019). Data collection occurred between July 2019 and January 2020.

\subsection{Participants and recruitment}

Inclusion criteria for providers included (1) being a lead teacher at a childcare center (CCC) or family childcare home (FCCH) which served children aged zero to five within a metropolitan area in which the study took place and (2) willing to provide contact information of a parent from their facility who would also participate in the study. Inclusion criteria for parents included having a child enrolled in the lead teacher's classroom. One provider and one parent were recruited from each childcare facility. As previous research has found that conducting at least eight interviews resulted in 80\% data saturation, 12 providers and 12 parents were recruited for data collection (Namey et al., 2016). A total of 28 providers were contacted via email and 31 via phone with 12 noting initial interest and completing the interview. With the 12 providers ( $n=6 \mathrm{CCC}, n=6 \mathrm{FCCH}$ ), 12 parents of those facilities and who had children within the providers classroom were contacted for telephonic interviews. The study was approved by a University affiliated Institutional Review Board (IRB).

Researchers obtained lists of childcare programs from the Nebraska Nutrition and Physical Activity Self Assessment for Child Care (Go NAP SACC) trainers, Nebraska Department of Health and Human Services Roster of Licensed Childcare and Preschool Programs in Nebraska as well as online from Facebook. Childcare providers were contacted via email or phone to determine if they met inclusion criteria and determine if they were interested in participating in the study. Participants were selected based on maximum variation purposive sampling with a goal of having half of participants from the CCC setting and half of participants from the FCCH setting in order to ensure broad representation and application across settings (Robert Wood Johnson Foundation, n.d.). 
For participating childcare providers, a narrative consent was read aloud to providers, and if they provided verbal assent, a time and day were determined for the interview to take place in person at the provider's facility. After completion of the provider interview, the researcher asked the provider for the contact information of the parent to participate in a similar interview. The primary investigator then contacted parents via text message, and a similar process regarding study explanation and acquiring verbal assent was completed via telephone.

\subsection{Instruments}

Before the start of the interview, participants completed a demographic form ( $n=12$ questions providers, $n=10$ for parents) including questions regarding their gender, education, and ethnicity. The interview guide was developed based off of the Social Ecological Model (SEM) and previous studies exploring family engagement (Table 2) (Dev et al., 2014; Garcia et al., 2018; Johnson et al., 2013; Lyn et al., 2013). The SEM consists of five different levels that are posited to interact to influence individuals' or groups' behavior (McLeroy et al., 1988). The five levels are (1) individual factors (e.g. individuals' knowledge, attitudes, and behaviors), (2) interpersonal factors (e.g. social networks, family, friends, and work colleagues), (3) institutional factors (e.g. organizational procedures and administrative supports), (4) community factors (e.g. relationships between different organizations), and (5) policy factors (e.g. local, state, national laws, and policies). This was operationalized by assessing caregivers' knowledge on healthy eating and physical activity on the individual level, relationship and communication between parents and providers on the interpersonal level, and providers' collaboration with organizations on the community level. To reduce participant burden, questions regarding the policy factors were not included in this study. The interview guide consisted of 20 total questions with 6 at the individual level, 12 at the interpersonal level, and 2 at the community level. Family engagement strategies were primarily explored at the institutional level (e.g. organizational policies). The childcare provider guide included a card-sort task (Dev et al., 2014). Childcare providers were given cards with each of the six NAEYC (n.d.-b) best practice family engagement 
Table 1 National Association for the Education of Young Children: Six principles of effective family engagement Principle Description

1. Programs invite families to participate in decision making and goal setting for their child.

2. Providers and programs engage families in two-way communication.

3. Programs and providers engage families in ways that are truly reciprocal.

4. Programs provide learning activities for the home and in the community.

5. Programs invite families to participate in program-level decisions and wider advocacy efforts.

6. Programs implement a comprehensive program-level system of family engagement.
Programs invite families to actively take part in making decisions concerning their children's education. Teachers and families jointly set goals for children's education and learning both at home and at school.

Strategies allow for both center- and family-initiated communication that is timely and continuous. Conversations focus on a child's educational experience as well as the larger program. Communication takes multiple forms and reflects each family's language preference.

Programs and families benefit from shared resources and information. Programs invite families to share their unique knowledge and skills and encourage active participation in the life of the center. Providers seek information about children's lives, families, and communities and integrate this information into their curriculum and teaching practices.

Programs use learning activities at home and in the community to enhance each child's early learning and encourage and support families' efforts to create a learning environment beyond the program.

Programs invite families to actively participate in making decisions about the program itself. Programs also invite families to advocate for early childhood education in the wider community.

Programs institutionalize family engagement policies and practices and ensure that providers, directors, and other staff receive the supports they need to fully engage families.

principles (Table 1) listed on it and sorted the card into 'uses', 'does not use', 'unsure about', or 'haven't heard about'. Next the researcher asked the participant to sort the 'uses' pile into 'easy to do', 'sometimes hard to do', or 'really hard to do' followed by additional probing questions. Parents were read each principle aloud and asked about if or how their provider or childcare facility took part in this principle.

\subsection{Procedures}

The researcher who conducted the interviews was a female undergraduate student in public health. She did not know the participants 
in any formal or informal capacity prior to the interview. She received training on conducting qualitative interviews, practiced interviews, and received feedback on her interviews by the first author, an experienced qualitative researcher with over 10 years of qualitative experience.

Once the interview guide was completed, using a cognitive interview approach, three pilot tests ( 2 parents and 1 childcare provider) were conducted using the 'think aloud' approach (Willis, 1999), to evaluate face validity and gauge duration of the interviews. Minor changes were made to the wording prior to beginning data collection including changing the word nutrition to healthy eating and removing several questions that were repetitive. Provider interviews were completed in person, whereas parent interviews were conducted over the phone for convenience. To reduce social desirability bias, the interviewer attempted to establish rapport with participants and if the interviewer detected a response due to social desirability bias, attempts were made to elicit a more authentic response (Bergen \& Labonté, 2020). Interviews ranged from 25 to $67 \mathrm{~min}$ and were audio recorded

\subsection{Data analysis}

The interviews were transcribed verbatim and uploaded into QSR Nvivo 12. Overall, data analysis followed a directed content analysis approach (Assarroudi et al., 2018; Hsieh \& Shannon, 2005). Interviewing and data analysis occurred concurrently to ensure data saturation was achieved in both groups with the initial proposed sample size (Hennink et al., 2017). All transcripts were coded utilizing the same codes for both parent and provider responses guided by best-practice strategies for conducting a directed content analysis (Assarroudi et al., 2018; Hsieh \& Shannon, 2005). First, the second author immersed herself in the data by reading through the interviews several times. Next, she developed a formative categorization matrix in which she utilized a deductive analysis approach to develop main categories according to the SEM levels (individual, intrapersonal, institutional, and community) and sub-categories guided by the topics (e.g. caregivers' knowledge on healthy eating and physical activity, relationship between parents and providers, providers' collaboration with community organizations, use of NAEYC family engagement principles) 
Table 2 Interview guide following the social ecological model

\section{Individual}

How do you define healthy eating?

How do you think healthy eating influences a child's development?

How do you define the term physical activity?

How do you think physical activity influences a child's development?

Are you aware of any national recommendations for serving healthy food in childcare? Please explain.

Are you aware of any national recommendations regarding physical activity in childcare? Please explain.

\section{Interpersonal}

Who do you think has the greatest influence over children's eating habits?

Who do you think has the greatest influence over children's physical activity levels?

What do you think the parent's role is in promoting healthy eating?

What do you think the parent's role is in promoting physical activity?

What challenges do you think parents have with trying to promote healthy eating choices at home with their child(ren)?

What challenges do you think parents have with trying to promote physical activity with their child(ren)?

What do you think is your (childcare providers') role in helping children establish healthy eating habits?

What do you think is your (childcare providers') role in providing physical activity for the children at your facility?

How do you/your childcare provider encourage families to promote healthy eating with their children

How do you/your childcare provider encourage families to promote physical activity with their children?

Outside of pick up and drop off, please describe how you/center communicate with children's parents.

What challenges have you had communicating with parents/childcare providers?

\section{Institutional (card sorting task)}

Here is a stack of cards that list effective principles regarding family engagement practices. Could you put these cards into three piles:

1. One pile for principles that your center uses,

2. One for principles that the center does not use, and

3. One for principles that you have not heard about or are unsure about.

\section{Community}

Have you/your childcare provider ever worked with a community organization to provide family engagement opportunities?

What community organizations would you/your childcare provider like to partner with to promote physical activity and healthy eating with the children in your care and their families? 
within the interview guide. Next, she developed a codebook with definitions of main categories and subcategories and then coded all data into these categories and sub-categories. Once this initial coding was complete, the first author reviewed the codebook and all coding to ensure all data were coded within the appropriate category or sub-category. Next, the second author utilized inductive coding to identify codes underneath the existing sub-categories. For example, underneath the sub-category of physical activity impact on child development, codes were developed for cognitive, language and communication, movement and physical development, and social and emotional. After this, she revised the codebook to include the additional codes with corresponding definitions. Following this coding, the first author again reviewed the codebook and all coding. She documented all discrepancies where either the codebook and/or coding were not clear. Then the two met to discuss these discrepancies, revise the codebook when appropriate, and come to a consensus on all coding. After the codebook was revised, both authors reviewed all coding one more time to ensure coding aligned with the codebook and that appropriate links were made between codes, sub-categories, and overall categories. Finally, the codebook and codes were shared with the third author, who reviewed the codebook and codes and agreed with the existing coding. Coding was conducted across all transcripts prior to comparing between groups (Lim et al., 2013; Lindsay, 2019)

Once data analysis was complete, the research team reviewed the codes to identify differences in responses between parents and providers. To facilitate this comparison, the percentage of respondents for each category were calculated and then compared between parents and providers (Table S1). Then researchers reviewed the coding to further compare differences between responses. Data were validated through the process of peer debriefing by the review and discussion of codes with a third reviewer (third author) and thick description by providing a detailed description of the data collection and results (Creswell, 2013). Strategies to enhance credibility and dependability were used throughout the study to support trustworthiness in the findings (Korstjens \& Moser, 2018). To enhance credibility data triangulation occurred through the use of multiple data sources from different sites ( $\mathrm{CCC}$ and $\mathrm{FCCH}$ ) and persons (parents and providers) as well as investigator triangulation by using three different researchers 
Table 3 Characteristics of child care setting and demographics of child care providers and parents $(n=12)$

Total

\begin{tabular}{lr} 
Child care settings & \\
Child and adult care food program & $11(91.7)$ \\
$\quad$ Yes & $1(8.3)$ \\
$\quad$ No & \\
Step up to quality & $9(75.0)$ \\
$\quad$ Yes & $3(25.0)$ \\
$\quad$ No & \\
Child care providers & $12(100.0)$ \\
Gender: Female & \\
Education & $2(16.7)$ \\
$\quad$ High school degree & $4(33.3)$ \\
$\quad$ Some college & $6(50.0)$ \\
$\quad$ College degree (associate or bachelors) & \\
Ethnicity & $2(16.7)$ \\
$\quad$ Black & $8(66.6)$ \\
$\quad$ White & $2(16.7)$ \\
$\quad$ Hispanic & \\
Parents & $12(100.0)$ \\
Gender: Female & \\
Education & $1(8.3)$ \\
High school degree & $3(25.0)$ \\
Some college & $8(66.7)$ \\
College degree (associate or bachelors) & \\
Ethnicity & $3(25.0)$ \\
$\quad$ Black & $8(66.7)$ \\
White & $1(8.3)$ \\
$\quad$ Hispanic & \\
\hline
\end{tabular}

a. Step up to quality is the state's quality rating improvement system.

in the analysis process (Korstjens \& Moser, 2018). To enhance dependability, records of each step of the research study including changes in data analysis were kept and reported accordingly.

\section{Results}

A total of 24 participants, 12 childcare providers and 12 parents, completed interviews (Table 3). A majority of childcare facilities were a part of the Child and Adult Care Food Program (91.7\%) and were a part of the quality rating improvement system for the state $(75.0 \%)$. 
All participants were female (100.0\%), whereas a majority were white $(66.7 \%)$, and had at least some college $(83.3 \%)$. An overview of all results are provided in Table $\mathrm{S} 1$.

Overall, both similarities and differences were found across all SEM levels. At the individual level, more providers than parents were aware of national recommendations for healthy eating compared with parents. However, a majority of both providers and parents were not aware of recommendations for physical activity and only about half of all participants were aware of recommendations for screen time. At the interpersonal level, for healthy eating, providers and parents mentioned family as the primary influence with only a few parents mentioning providers as influential. Conversely, for physical activity, providers mentioned family, providers, and parents as influential on children's physical activity, whereas parents only mentioned family and peers. At the institutional level, there was a high level of agreement between providers and parents that childcare providers were engaged in 5 of the 6 best practice family engagement principles. Finally, at the community level more parents than providers mentioned their childcare facilities had engaged with community organizations and were unsure of types of community organizations childcare providers could partner with. Findings at each level are discussed in more detail below.

\subsection{Individual}

\subsubsection{Knowledge of healthy eating and physical activity definitions}

With respect to knowledge of healthy eating, all participants primarily mentioned healthy eating in the context of food groups or as eating in moderation. Further, both providers and parents agreed that healthy eating influenced a child's physical development, cognitive development, and social and emotional development. Regarding differences, providers $(75 \%)$ more often referred to eating within specific food groups compared with parents (42\%). Although parents more often referred to moderation (50\%, 17\% respectively). Not surprisingly, providers $(83 \%)$ were more likely to state that they were aware of the national recommendations for food compared with parents $(50 \%)$.

Similarities in respect to knowledge and recommendations of physical activity were found between parents and providers. Participants 
similarly defined physical activity as high intensity activities such as 'running' (parent). An additional similarity was a majority of both providers and parents were unaware of the national recommendations for physical activity and a little over half of providers and parents were aware of national recommendations for screen time. However, several differences in knowledge were also found between providers and parents. Providers were more likely to define physical activity as motion or movement $(58 \%)$ in comparison to parents $(25 \%)$, whereas parents more often referenced sports and no providers mentioned this. Providers felt that physical activity primarily helped with physical development (83\%), cognitive development (42\%) and language and communication (25\%). Parents primarily thought physical activity impacted social and emotional development (58\%), and cognitive development (25\%). No parents mentioned an influence on language and communication skills, whereas only one provider mentioned an impact on social and emotional development.

\subsection{Interpersonal}

\subsubsection{Healthy eating and physical activity influences}

When asked who had the most influence of children's healthy eating behaviors, providers and parents primarily mentioned family. Conversely, providers also mentioned that parents and providers were a primary influence; however, only a few parents mentioned providers as influencing their child's eating. One provider mentioned, 'I think the parents, we can too, but I think the first need is at home'. Additionally, a few parents thought that peers were the primary influence on their child's eating behaviors. One parent described, '... my daughter loves peas but somebody made fun of her at school for liking peas so now she doesn't eat peas at school .... Providers and parents had less agreement in regarding to who had the biggest influence on children's physical activity. Providers mentioned the entire family (33\%), providers and parents (33\%), or just the provider (25\%). For example, one provider mentioned, 'I would say parents and their teachers, because again those are the two main people who are in their lives, they go home with parents, but they are here with us $8 \mathrm{~h}$ of the day'. Conversely, parents thought family $(75 \%)$ or peers $(17 \%)$ were the biggest influencers and once again did not refer to providers. 
3.2.2 Providers' and parents' role in healthy eating and physical activity

Participants were asked how providers and parents should or were promoting healthy eating. Concerning the providers' role, providers and parents agreed the providers serve as role models and should provide healthy options. Providers more often mentioned that their role was also to present family style dining (25\%) compared with only $8 \%$ of parents. In regard to parents' role in healthy eating, both providers and parents discussed the importance of parents encouraging eating healthy foods, and role modelling of eating healthy foods. One provider mentioned, 'If they are not eating healthy at home, then they are not going to want to eat the food we have here'. A majority of parents also stated they promoted healthy eating by providing healthy food ( $83 \%$ ); however, only 33\% of providers mentioned parents' provision of healthy food.

When discussing providers' role in physical activity, providers and parents had different perceptions. Providers primarily discussed that their role in promoting physical activity to children was to role model physical activity (58\%) and provide options (33\%). Conversely, more parents mentioned providers role in promoting physical activity was to provide options for physical activity (67\%) compared with role modelling (42\%). For example, one parent discussed the importance of providing options, 'It is about them providing options. Making sure to take advantage of good weather days, get them outside, you know giving them opportunities'.

When discussing parents' roles for physical activity, both providers and parents thought parents promoted physical activity through role modelling. However, more parents than providers $(67 \%, 17 \%)$ reported the provision of physical activity as a way they as parents promoted physical activity. Interestingly, two providers specifically mentioned how they felt parents might have difficulties promoting healthy eating and physical activity as one provider mentioned, 'We try to talk to them (parents) when we learn about something okay you can repeat this at home, do this or do this, and not every parent does it, but some parents can'. 
3.2.3 Challenges to promotion of healthy eating and physical activity for parents

Relatedly participants were asked about challenges that parents face promoting healthy eating and physical activity. In regard to healthy eating, both providers and parents thought time was an issue for parents. More providers (42\%) than parents (17\%) mentioned the expense of healthy foods was a challenge for parents. More parents $(42 \%)$ than providers $(17 \%)$ mentioned the child's wants as a challenge. For instance a parent said, 'Obviously my kid would rather have a pop-tart than celery'. Regarding physical activity, providers believed time was the biggest barrier for parents (75\%) but only $17 \%$ of parents mentioned this as a barrier. Parents mentioned various barriers such as being tired, their child not wanting to participate, the weather, or no barriers at all.

\subsubsection{Providers' encouragement of healthy eating and physical activity}

Providers and parents also discussed how providers encouraged healthy eating and physical activity. Approximately half of providers and parents mentioned, providers engaged in verbal discussion or encouragement of trying healthy foods at home and activities they did at their childcare facility that could be tried within the home. Of those parents who reported discussing activities with their providers, most mentioned actually trying these activities at home. For example, one parent said, 'One day they did like a train thing with these little cars outside and my son was pulling the kids up so we did [the activity] that night too so seeing things they are doing fun outside knowing that they are having fun doing it there then we take it home and do it ourselves'. In regard to healthy eating, a quarter of providers, but only one parent mentioned providers also encouraged healthy eating by promoting family style dining. Similarly, more providers than parents mentioned the childcare facility shared government or other local organization healthy eating resources with families. Further, half of providers and a majority of parents reported that no other resources had been shared pertaining to physical activity at home. One provider mentioned, 'Yeah a few fliers. I probably find them more in my driveway ....' 


\subsubsection{Communication between providers and parents}

Participants discussed the type of communication that typically occurs outside of and during drop off and pick-up time. Outside of pickup and drop-off time, communication occurred in a variety of different ways including phone calls, text messages, apps (e.g. ClassDoJo), newsletters, e-mails, Facebook, or through support staff without any major differences between provider and parent responses. When discussing communication during pick-up and drop-off though, several differences were found. A majority of providers and half of parents stated they typically verbally discussed any updates during this time. An additional third of childcare providers reported using daily sheets, whereas only $17 \%$ of parents mentioned their provider used daily sheets.

Regardless of the type of communication channel, most providers felt there were challenges to communicating. The majority of providers thought some of the barriers were due to parents' behaviors such as not communicating with them, not taking their advice, or not taking healthy eating and physical activity seriously. For example, one CCC provider mentioned, '... the other challenge would be the parents who do not want to make time to talk to you about their child'. Another challenge primarily mentioned by providers was the challenge of having difficult conversations with parents about their child's behavior. A majority of parents reported they did not experience challenges communicating with their childcare provider.

\subsection{Institutional}

To understand institutional practices, providers were asked about if or how they implemented NAEYC's six family engagement principles, whereas parents were asked if their providers use these principles. In regard to their overall knowledge of the NAEYC principles, a majority of providers (67\%) said they were aware of the principles compared with $25 \%$ of parents. Table 4 provides the percentages of parents and providers who mentioned their childcare facility used each of the principles. Overall, there was a high-level of agreement between parents and providers on whether or not the childcare facilities used principles 1-5. For principle 6, concerning a comprehensive program-level system, fewer providers than parents identified that their childcare facility used this principle. 
Table 4 Percent of providers and parents who said their childcare facility uses each of the NAEYC family engagement principles

\begin{tabular}{lcr} 
Principle & Provider (\%) & Parent (\%) \\
\hline $\begin{array}{l}\text { 1. Programs invite families to participate in decision making } \\
\text { and goal setting for their child. }\end{array}$ & 82 & 82 \\
$\begin{array}{l}\text { 2. Providers and programs engage families in two-way } \\
\text { communication. }\end{array}$ & 90 & 100 \\
$\begin{array}{l}\text { 3. Programs and providers engage families in ways that are } \\
\text { truly reciprocal. }\end{array}$ & 100 & 90 \\
$\begin{array}{l}\text { 4. Programs provide learning activities for the home and } \\
\text { in the community. }\end{array}$ & 73 & 64 \\
$\begin{array}{l}\text { 5. Programs invite families to participate in program-level } \\
\quad \text { decisions and wider advocacy efforts. }\end{array}$ & 36 & 45 \\
$\begin{array}{l}\text { 6. Programs implement a comprehensive program-level } \\
\text { system of family engagement. }\end{array}$ & 45 & 73
\end{tabular}

\subsection{Community}

When asked if providers had previously or were currently utilizing any community organizations that engage families, several differences between providers and parents were found. Fewer providers (25\%) than parents (58\%) mentioned their childcare facilities had engaged with community organizations. The types of activities mentioned varied widely from having, 'a lady that comes and teach the kids like yoga and the parents can come to it too' (parent) to discussing utilizing local farmers market or food stands as one parent mentioned, 'She will say local farms or local produce stands are here and there and we will talk about what she is going to be getting from there'. When asked about potential community organizations to promote healthy eating and physical activity, a third of providers were unsure of organizations they could partner with whereas a majority of parents were unsure. Providers had a wide variety of ideas ranging from partnering with the local YMCA or partnering with organizations like Home Depot to take part in gardening classes for kids. 


\section{Discussion}

The purpose of this study was to compare childcare provider and parent perceptions of communication regarding healthy eating and physical activity as well as use of best practice strategies on family engagement for these topics. When exploring provider and parent knowledge of healthy eating and physical activity it is important to note that a majority of providers but only half of parents were aware of national food guidelines. Similar to other research, a majority of providers and parents were not aware of the physical activity guidelines for children (Dwyer et al., 2008; Joseph et al., 2019). Childcare providers' knowledge of nutrition guidelines is likely a reflection of the high percentage of providers who participated in the Child and Adult Food Care Program, which requires training on this topic. Given professional development on nutrition is related to parent engagement, the topic of nutrition and recommendations for healthy eating might be a feasible topic for providers to communicate this knowledge to with parents (Garcia et al., 2018). The lack of knowledge of physical activity guidelines is likely also a reflection of the lack of mandated training on physical activity within the state that the study took place. This is important as a recent study found that early childhood education candidates who had training related to physical activity were more likely to report higher perceived importance and personal responsibility for teaching physical activity (Bruijns et al., 2020). Given evidence that childcare providers are interested in physical activity trainings (Bruijns et al., 2020; Fees et al., 2009), efforts are needed to ensure physical activity trainings are provided and promoted to childcare providers.

Another important finding was in reference to discussion on providers and parents perceptions of people who influenced children's health behaviors. Although both providers and parents recognized the importance of parents, few parents recognized the providers' role in influencing their child's healthy eating and physical activity behaviors. Given the amount of time children spend in childcare, research supports the critical role that providers play in children's development (O’Neill et al., 2016; Sisson et al., 2017). Future efforts are needed to educate parents about the role and importance of not only their family but childcare providers on children's health behaviors (Rhodes et al., 2020; Sisson et al., 2017). 
Providers and parents had several different perceptions of their counterpart's role in healthy eating and physical activity. For example, more parents than providers thought an important role for providers was offering options for physical activity. On a similar note for parents' role, more parents than providers reported parents offered physical activity to their children. These differences really underscore the potential lack of communication between providers and parents on how each entity supports children's healthy eating and physical activity. Future efforts could consider increased communication on daily activities within the childcare setting and at home. These efforts could be as simple as parents letting childcare providers know their child is participating in a new activity such as a soccer league. Additional discussion could also occur during semi-annual parent-provider conferences.

Both providers and parents agreed parents had challenges to promoting healthy eating and physical activity; yet again, there were also differences. Both groups agreed time was the biggest barrier to healthy eating (Ling et al., 2016). However, although most providers thought time was also a barrier for promoting physical activity, only a few parents reported this as a barrier. This is in contrast to other research that found parents viewed their busy lifestyle as a barrier to physical activity (Joseph et al., 2019). Other differences were in regard to more providers than parents mentioning the expense of food and more parents than providers mentioning children's wants as challenges to healthy eating. Understanding parents' perceived challenges to promoting healthy behaviors could provide critical information for providers who may be able to help parents with these challenges given their knowledge and experience working with a number of families (Dev et al., 2017). Future efforts could encourage childcare providers to speak with parents about the challenges they experience to determine if they are able to either verbally encourage or provide informational sessions for parents.

Discussion of providers' encouragement of healthy eating and physical activity also led to several interesting findings. First, a quarter of providers but only one parent mentioned providers encouraged healthy eating by promoting family style dining, a responsive feeding practice recommended by the Child and Adult Care Food Program. Similar to other research on healthy eating, there appeared to be a 
lack of resource sharing by providers partially due to not having the proper resources to offer parents (Dev et al., 2014, 2017). There is a need for readily accessible resources for providers that address easily implementable strategies for children's healthy eating and physical activity to improve family engagement in these behaviors.

In regard to methods of communication, similar to other research providers and parents reported using various methods (Barnes et al., 2016; Mena et al., 2020). However, in this study, a third of childcare providers reported using daily sheets but fewer parents mentioned this type of communication. Previous research has also found that childcare providers thought paper/print forms of communication were the most successful forms of communication (Barnes et al., 2016). Our finding is important as if providers are spending their time on such sheets and they are not being utilized, additional avenues of communication may need to be explored.

Further, although a majority of parents noted no challenges communicating with their providers, a third of providers did feel it was a challenge having difficult conversations with the parents they work with. In addition, a majority of providers expressed a concern that parents do not communicate with them enough, are not always taking their advice, or are not taking healthy eating and physical activity seriously (Dev et al., 2017; Dwyer et al., 2008; Johnson et al., 2013; Sisson et al., 2017). Professional development opportunities to improve providers' confidence in approaching and communicating with parents are needed. Further owing to COVID-19 and increased need to report updates on health and safety information of children, supplemental communication through messaging may and/or could be utilized. Providers may want to prioritize the parent preferred methods of communication that parents are most comfortable using in order to bolster relationships and the exchange of information.

Interestingly, more parents than providers mentioned their childcare facility had engaged with community organizations. However, providers and parents were not aware of community organizations that could be promoted to engage families in healthy eating or physical activity. Community organizations such as Park and Recreation departments or libraries may be potential options for childcare providers to partner with to support early childhood health behaviors (NAEYC, n.d.-a). Future efforts are needed to determine how providers 
could collaborate with community organizations to support parents in promoting healthy behaviors. For example, a study of Hart et al. (2015) found parents desired information in regard to how to promote healthy eating and avoid encouraging a negative body image. As providers' may not have this specific expertise, community partners such as local mental health practitioners, registered dietitians and nutritionists, or universities might be able to provide already or easily developed resources to parents (Hart et al., 2015).

There were several strengths of this study. First, this is one of the first studies to collectively present and compare perceptions of parents and childcare providers regarding healthy eating and physical activity within one study. Another strength of this study was the inclusion of providers and parents from family childcare homes and childcare centers. The sample allowed an opportunity to see common themes across the types of facilities. Future research should further explore the types of strategies that might be needed to facilitate family engagement in different facility types (e.g. FCCH and CCC). This study also had several limitations. One limitation was that the recruitment of parents was dependent on the contact information that the childcare providers offered. Thus, childcare providers likely provided contact information for parents who they have good rapport with, thus this may have been reflected in the findings. Another limitation is that all childcare providers and parents resided within the same Midwest metropolitan area and it was a relatively small sample. Findings from this study are likely not generalizable and may not be applicable to residents within other geographical areas. Although data were collected prior to COVID-19, further research regarding strategies to support providers and parents in family engagement using novel approaches from a more diverse audience within the context of social distancing is needed. Finally, given that only _20\% of providers who were contacted, participated in the study, participants may have been more interested in this topic and thus results may not reflect all childcare providers.

In conclusion, this study found several similarities and differences in providers' and parents' perceptions of communication and family engagement in healthy eating and physical activity. These results provide further evidence of the need for increased communication not only between providers and parents but also for parents to fully 
understand the impact that providers have on their children's health behaviors. Future research efforts should help in identifying appropriate ways to discuss difficult topics and find common grounds for providers and parents as well as how providers can continue to facilitate parents' engagement in promoting healthy eating and physical activity.

Acknowledgments We would like to thank the childcare providers and parents for their time and efforts with this study. This study was funded by the Fund for Undergraduate Scholarly Excellence grant from the University of Nebraska at Omaha.

Conflict of Interests The authors have no conflict of interests to report.

Ethics Statement This study was approved by the University of Nebraska Medical Center Institutional Review Board.

Patient Consent All participants completed a narrative consent prior to participation in this study.

Data Availability Data available from the lead author upon request.

\section{References}

Assarroudi, A., Nabavi, F. H., Armat, M. R., Ebadi, A., \& Vaismoradi, M. (2018). Directed qualitative content analysis: The description and elaboration of its underpinning methods and data analysis process. Journal of Research in Nursing, 23(1), 42-55. https://doi.org/10.1177/1744987117741667

Barnes, J. K., Guin, A., Allen, K., \& Jolly, C. (2016). Engaging parents in early childhood education: Perspectives of childcare providers. Family and Consumer Sciences Research Journal, 44(4), 36o-374. https://doi.org/10.1111/fcsr.12164

Bergen, N., \& Labonté, R. (2020). "Everything is perfect, and we have no problems": Detecting and limiting social desirability Bias in qualitative research. Qualitative Health Research, 30(5), 783-792. https://doi. org/10.1177/1049732319889354

Bruijns, B., Adamo, K., Burke, S. M., Carson, V., Irwin, J. D., Naylor, P.-J., Timmons, B. W., Vanderloo, L. M., \& Tucker, P. (2020). Early childhood education candidates' perspectives of their importance and responsibility for promoting physical activity and minimizing screen-viewing opportunities in childcare. Retrieved September 25, 2020, from https://www.tandfonline.com/doi/full/10 $.1080 / 10901027.2020 .1818651$ 
Child Care Licensing (2020). Retrieved September 17, 2020, from http://dhhs. ne.gov:80/licensure/Pages/Child-Care-Licensing.aspx

Creswell, J. (2013). Qualitative inquiry and research design: Choosing among five approaches (third). SAGE Publications Inc.

Dev, D. A., McBride, B. A., Speirs, K. E., Donovan, S. M., \& Cho, H. K. (2014). Predictors of head start and child-care providers' healthful and controlling feeding practices with children aged 2 to 5 years. Journal of the academy of nutrition and dietetics, 114(9), 1396-1403. https://doi.org/10.1016/j. jand.2014.01.006

Dev, D. A., Byrd-Williams, C., Ramsay, S., McBride, B., Srivastava, D., Murriel, A., Arcan, C., \& Adachi-Mejia, A. M. (2017). Engaging parents to promote Children's nutrition and health: Providers' barriers and strategies in head start and child care centers. American Journal of Health Promotion, 31(2), 153-162. https://doi.org/10.1177/0890117116685426

Dwyer, G. M., Higgs, J., Hardy, L. L., \& Baur, L. A. (2008). What do parents and preschool staff tell us about young children's physical activity: A qualitative study. The International Journal of Behavioral Nutrition and Physical Activity, 5, 66. https://doi.org/10.1186/1479-5868-5-66

Fees, B., Trost, S., Bopp, M., \& Dzewaltowski, D. A. (2009). Physical activity programming in family child care homes: Providers' perceptions of practices and barriers. Journal of Nutrition Education and Behavior, 41(4), 268-273. https://doi.org/10.1016/j.jneb.2008.01.013

Garcia, A. S., Dev, D. A., \& Stage, V. C. (2018). Predictors of parent engagement based on child care providers' perspectives. Journal of Nutrition Education and Behavior, 50(9), 905-912. https://doi.org/10.1016/j.jneb.2018.06.009

Given, L. M. (2008). Perception. In The SAGE Encyclopedia of Qualitative Research Methods.

Hart, L. M., Damiano, S. R., Cornell, C., \& Paxton, S. J. (2015). What parents know and want to learn about healthy eating and body image in preschool children: A triangulated qualitative study with parents and early childhood professionals. BMC Public Health, 15, 596. https://doi.org/10.1186/s12889-015-1865-4

Head Start Early Childhood Learning \& Knowledge Center. (n.d.). Family engagement. https://eclkc.ohs.acf.hhs.gov/family-engagement

Hennink, M. M., Kaiser, B. N., \& Marconi, V. C. (2017). Code saturation versus meaning saturation: How many interviews are enough? Qualitative Health Research, 27(4), 591-6o8. https://doi.org/10.1177/1049732316665344

Hennink-Kaminski, H., Vaughn, A. E., Hales, D., Moore, R. H., Luecking, C. T., \& Ward, D. S. (2018). Parent and child care provider partnerships: Protocol for the healthy me, healthy we (HMHW) cluster randomized control trial. Contemporary Clinical Trials, 64, 49-57. https://doi.org/10.1016/j. cct.2017.11.007

Hsieh, H. F., \& Shannon, S. E. (2005). Three approaches to qualitative content analysis. Qualitative Health Research, 15(9), 1277-1288. [pii]. https://doi. org/10.1177/1049732305276687 
Jayasuriya, A., Williams, M., Edwards, T., \& Tandon, P. (2016). Parents' perceptions of preschool activities: Exploring outdoor play. Early Education and Development, 27(7), 1004-1017. https://doi.org/10.1080/10409289.2016.1 156989

Johnson, S. L., Ramsay, S., Shultz, J. A., Branen, L. J., \& Fletcher, J. W. (2013). Creating potential for common ground and communication between early childhood program staff and parents about young children's eating. Journal of Nutrition Education and Behavior, 45(6), 558-570. https://doi.org/10.1016/j. jneb.2013.02.009

Joseph, E. D., Kracht, C. L., St. Romain, J., Allen, A. T., Barbaree, C., Martin, C. K., \& Staiano, A. E. (2019). Young children's screen time and physical activity: perspectives of parents and early care and education center providers. Global Pediatric Health, 6, 1-13. https://doi.org/10.1177/2333794X19865856

Korstjens, I., \& Moser, A. (2018). Series: Practical guidance to qualitative research. Part 4: Trustworthiness and publishing. European Journal of General Practice, 24(1), 120-124. https://doi.org/10.1080/13814788.2017.1375092

Lim, J., Gonzalez, P., Wang-Letzkus, M. F., Baik, O., \& Ashing-Giwa, K. T. (2013). Health behavior changes following breast cancer treatment: A qualitative comparison among Chinese American, Korean American, and Mexican American survivors. Journal of Health Care for the Poor and Underserved, 24(2), 599-618. https://doi.org/10.1353/hpu.2013.0094

Lindsay, S. (2019). Five approaches to qualitative comparison groups in health research: A scoping review. Qualitative Health Research, 29(3), 455-468. https://doi.org/10.1177/1049732318807208

Ling, J., Robbins, L. B., \& Hines-Martin, V. (2016). Perceived parental barriers to and strategies for supporting physical activity and healthy eating among head start children. Journal of Community Health, 41(3), 593-602. https://doi. org/10.1007/s10900-015-0134-X

Luecking, C. T., Dobson, P., \& Ward, D. S. (2020). Barriers and facilitators of parent engagement with health promotion in child care: A mixed-methods evaluation. Health Education \& Behavior, 47(6), 914-926. https://doi. org/10.1177/1090198120952040

Lyn, R., Maalouf, J., Evers, S., Davis, J., \& Griffin, M. (2013). Nutrition and physical activity in child care centers: The impact of a wellness policy initiative on environment and policy assessment and observation outcomes, 2011. Preventing Chronic Disease, 10, 12032. https://doi.org/10.5888/pcd10.120232

McLeroy, K. R., Bibeau, D., Steckler, A., \& Glanz, K. (1988). An ecological perspective on health promotion program. Health Education \& Behavior, 15(4), 351-377.

Mena, N. Z., Risica, P. M., Gans, K. M., Lofgren, I. E., Gorman, K., Tobar, F. K., \& Tovar, A. (2020). Communication with family child care providers and feeding preschool-aged children: Parental perspectives. Journal of Nutrition Education and Behavior, 52(1), 10-20. https://doi.org/10.1016/j.jneb.2019.10.015 
Namey, E., Guest, G., McKenna, K., \& Chen, M. (2016). Evaluating bank for your buck: A cost-effectiveness comparison between individual interviews and focus groups based on thematic saturation levels. American Journal of Evaluation, 37(3), 425-440. https://doi.org/10.1177/1098214016630406

National Association for the Education of Young Children. (n.d.-a). Retrieved September 25, 2020, from https://www.naeyc.org/resources/blog/ family-engagement-system

National Association for the Education of Young Children. (n.d.-b). Retrieved September 17, 2020, from https://www.naeyc.org/resources/topics/ family-engagement/principles

Ogden, C. L., Carroll, M. D., Kit, B. K., \& Flegal, K. M. (2014). Prevalence of childhood and adult obesity in the United States, 2011-2012. JAMA, 311(8), 8o6-814. https://doi.org/10.1001/jama.2014.732

O’Neill, J. R., Dowda, M., Benjamin Neelon, S. E., Neelon, B., \& Pate, R. R. (2016). Effects of a new state policy on physical activity practices in child care centers in South Carolina. American Journal of Public Health, 107(1), 144-146. https:// doi.org/10.2105/AJPH.2016.303521

Rhodes, R. E., Guerrero, M. D., Vanderloo, L. M., Barbeau, K., Birken, C. S., Chaput, J.-P., Faulkner, G., Janssen, I., Madigan, S., Mâsse, L. C., McHugh, T.L., Perdew, M., Stone, K., Shelley, J., Spinks, N., Tamminen, K. A., Tomasone, J. R., Ward, H., Welsh, F., \& Tremblay, M. S. (2020). Development of a consensus statement on the role of the family in the physical activity, sedentary, and sleep behaviours of children and youth. The International Journal of Behavioral Nutrition and Physical Activity, 17, 74. https://doi.org/10.1186/ s12966-020-00973-0

Robert Wood Johnson Foundation. (n.d.). Retrieved September 17, 2020, from http://www.qualres.org/HomeMaxi-3803.html

Sisson, S. B., Smith, C. L., \& Cheney, M. (2017). Big impact on small children: Child-care providers' perceptions of their role in early childhood healthy lifestyle behaviours. Child Care in Practice, 23(2), 162-180. https://doi.org/10.1 080/13575279.2017.1299111

Tandon, P. S., Saelens, B. E., \& Copeland, K. A. (2017). A comparison of parent and childcare provider's attitudes and perceptions about preschoolers' physical activity and outdoor time. Child: Care, Health and Development, 43(5), 679-686.

Vandeweghe, L., Moens, E., Braet, C., Van Lippevelde, W., Vervoort, L., \& Verbeken, S. (2016). Perceived effective and feasible strategies to promote healthy eating in young children: Focus groups with parents, family child care providers and daycare assistants. BMC Public Health, 16, 1045. https://doi. org/10.1186/s12889-016-3710-9

Willis, G. B. (1999). Cognitive interviewing: A "how to" guide. Research Triangle Institute. 
Wolfenden, L., Barnes, C., Jones, J., Finch, M., Wyse, R. J., Kingsland, M., Tzelepis, F., Grady, A., Hodder, R. K., Booth, D. \& Yoong, S. L. (2020). Strategies to improve the implementation of healthy eating, physical activity and obesity prevention policies, practices or programmes within childcare services. Cochrane Database of Systematic Reviews, (2), CDo11779. https://doi. org/10.1002/14651858.CD011779.pub3

World Health Organization. (2019). Early child development (Vol. 2019). https:// www.who.int/social determinants/themes/earlychilddevelopment/en/

Supporting Information: Supplemental Table 1. "Themes and results from semistructured interviews" - follows. 
Supplemental Table 1. Themes and results from semi-structured interviews

\begin{tabular}{|cccc|} 
Ecological Model & $\begin{array}{c}\text { Total } \\
(\mathrm{n}=24)\end{array}$ & $\begin{array}{c}\text { Provider } \\
(\mathrm{n}=12)\end{array}$ & $\begin{array}{c}\text { Parent } \\
(\mathrm{n}=12)\end{array}$ \\
\hline & Individual & & \\
\hline
\end{tabular}

\section{Knowledge}

Define healthy eating as specific food groups

as eating in moderation as awareness

Healthy eating impact on child development

Cognitive

Movement and physical development

Social and emotional

Define physical activity

as high intensity

as general motion or movement

as sport participation

Physical activity impact on child development

Cognitive

Language and communication

Movement and physical development

Social and emotional

\begin{tabular}{ccc}
$58 \%$ & $75 \%$ & $42 \%$ \\
$33 \%$ & $17 \%$ & $50 \%$ \\
$4 \%$ & $8 \%$ & $0 \%$ \\
$46 \%$ & $42 \%$ & $50 \%$ \\
$67 \%$ & $67 \%$ & $67 \%$ \\
$33 \%$ & $25 \%$ & $42 \%$ \\
& & \\
$42 \%$ & $42 \%$ & $42 \%$ \\
$42 \%$ & $58 \%$ & $25 \%$ \\
$8 \%$ & $0 \%$ & $17 \%$ \\
& & \\
$33 \%$ & $42 \%$ & $25 \%$ \\
$13 \%$ & $25 \%$ & $0 \%$ \\
$67 \%$ & $83 \%$ & $50 \%$ \\
$33 \%$ & $8 \%$ & $58 \%$ \\
& & \\
$25 \%$ & $8 \%$ & $42 \%$ \\
$67 \%$ & $83 \%$ & $50 \%$ \\
& & \\
$79 \%$ & $67 \%$ & $92 \%$ \\
$13 \%$ & $25 \%$ & $0 \%$ \\
\hline
\end{tabular}

National recommendations for food

Not aware

Aware

National recommendations for physical activity

Nor aware

Aware

\section{Interpersonal}

\section{Influence on healthy eating and physical activity}

Most influential of child's eating

Everyone

Family

Other kids

Parents and provider

Provider

Most influential of child's physical activity

Everyone

Family

Other kids

Parents and provider

Provider

Child

Parents' role in healthy eating and physical activity

How to promote healthy eating in home

Encouragement

$\begin{array}{ccc}8 \% & 8 \% & 8 \% \\ 54 \% & 50 \% & 59 \% \\ 8 \% & 0 \% & 17 \% \\ 21 \% & 42 \% & 0 \% \\ 8 \% & 0 \% & 17 \% \\ & & \\ 4 \% & 8 \% & 0 \% \\ 50 \% & 33 \% & 67 \% \\ 8 \% & 0 \% & 17 \% \\ 17 \% & 33 \% & 0 \% \\ 13 \% & 25 \% & 0 \% \\ 4 \% & 0 \% & 8 \% \\ & & \end{array}$

$29 \%$

$25 \%$

$33 \%$ 
Role model

Problem with parents

Provide healthy food

How to promote physical activity in home

Encouragement

Role model

Problem w parents

Provide physical activity

Challenges for parents to offering healthy eating

Perceived wants of child

Too expensive

Lack of knowledge

No challenges

Purchasing unhealthy options

Time

Challenges for parents offering physical activity

Child not wanting to

No challenges

Lack of knowledge

Time

Tired

Weather

Providers' role in healthy eating and physical activity

Provider's role in eating

Provide family style dining

Don't know

Provide healthy options

Role model

Providers' role in physical activity

Provide options

Role model

Teaching

Encourage healthy eating and physical activity

Verbal discussion

Family style dinning

State-gov resource

Communication at pick up and drop off

Mobile app

Daily sheet

Facebook messenger

Text

Verbal (in person)

Challenges with communicating

Difficult conversations

Difficult parents

Lack of communication

$\begin{array}{ccc}38 \% & 42 \% & 33 \% \\ 8 \% & 17 \% & 0 \% \\ 58 \% & 33 \% & 83 \% \\ & & \\ 13 \% & 25 \% & 0 \% \\ 50 \% & 58 \% & 42 \% \\ 8 \% & 17 \% & 0 \% \\ 42 \% & 17 \% & 67 \% \\ & & \\ 29 \% & 17 \% & 42 \% \\ 29 \% & 42 \% & 17 \% \\ 8 \% & 17 \% & 0 \% \\ 4 \% & 0 \% & 8 \% \\ 8 \% & 8 \% & 8 \% \\ 42 \% & 42 \% & 42 \% \\ & & \\ 13 \% & 8 \% & 17 \% \\ 8 \% & 0 \% & 17 \% \\ 8 \% & 17 \% & 0 \% \\ 46 \% & 75 \% & 17 \% \\ 25 \% & 17 \% & 33 \% \\ 8 \% & 0 \% & 17 \%\end{array}$

$17 \%$

$4 \%$

$46 \%$

$42 \%$

$50 \%$

$50 \%$

$5 \%$

$54 \%$

$17 \%$

$38 \%$

$13 \%$

$25 \%$

$4 \%$

$8 \%$

$58 \%$

$21 \%$

$42 \%$

$21 \%$
$33 \%$

$83 \%$

$0 \%$

$42 \%$

$0 \%$

$67 \%$

$2 \%$

$17 \%$

$0 \%$

$8 \%$

$8 \%$

$42 \%$

$17 \%$

$17 \%$

$0 \%$

$17 \%$

$17 \%$

$8 \%$

$8 \%$

$50 \%$

$42 \% \quad 42 \%$

$33 \% \quad 67 \%$

$58 \% \quad 42 \%$

$0 \% \quad 8 \%$

$50 \% \quad 58 \%$

$25 \% \quad 8 \%$

$58 \% \quad 17 \%$

$8 \% \quad 17 \%$

$33 \% \quad 17 \%$

$0 \% \quad 8 \%$

$17 \% \quad 0 \%$

$67 \% \quad 50 \%$

$33 \% \quad 8 \%$

$83 \% \quad 0 \%$

$25 \% \quad 17 \%$ 


\begin{tabular}{|c|c|c|c|}
\hline No challenges & $67 \%$ & $58 \%$ & $75 \%$ \\
\hline \multicolumn{4}{|c|}{ Community } \\
\hline \multicolumn{4}{|c|}{ Engagement with community organizations } \\
\hline Yes & $33 \%$ & $42 \%$ & $25 \%$ \\
\hline No & $67 \%$ & $58 \%$ & $75 \%$ \\
\hline \multicolumn{4}{|l|}{ Community orgs potentially partner with } \\
\hline Unsure & $67 \%$ & $33 \%$ & $50 \%$ \\
\hline Children's museum & $4 \%$ & $0 \%$ & $8 \%$ \\
\hline Cooking class & $4 \%$ & $0 \%$ & $8 \%$ \\
\hline Exercise class & $4 \%$ & $0 \%$ & $8 \%$ \\
\hline Gardening & $4 \%$ & $8 \%$ & $0 \%$ \\
\hline YMCA & $17 \%$ & $33 \%$ & $0 \%$ \\
\hline School system & $4 \%$ & $8 \%$ & $0 \%$ \\
\hline \multicolumn{4}{|c|}{ Institutional } \\
\hline Use of family engagement principles & $(n=22)$ & $(n=11)$ & $(n=11)$ \\
\hline \multicolumn{4}{|l|}{ Principle 1} \\
\hline Use & $82 \%$ & $82 \%$ & $82 \%$ \\
\hline Don't use & $14 \%$ & $18 \%$ & $9 \%$ \\
\hline Unsure & $4 \%$ & $0 \%$ & $9 \%$ \\
\hline \multicolumn{4}{|l|}{ Principle 2} \\
\hline Use & $96 \%$ & $90 \%$ & $100 \%$ \\
\hline Don't use & $0 \%$ & $0 \%$ & $0 \%$ \\
\hline Unsure & $4 \%$ & $9 \%$ & $0 \%$ \\
\hline \multicolumn{4}{|l|}{ Principle 3} \\
\hline Use & $96 \%$ & $100 \%$ & $90 \%$ \\
\hline Don't use & $4 \%$ & $0 \%$ & $9 \%$ \\
\hline Unsure & $0 \%$ & $0 \%$ & $0 \%$ \\
\hline \multicolumn{4}{|l|}{ Principle 4} \\
\hline Use & $68 \%$ & $73 \%$ & $67 \%$ \\
\hline Don't use & $14 \%$ & $9 \%$ & $18 \%$ \\
\hline Unsure & $18 \%$ & $18 \%$ & $18 \%$ \\
\hline \multicolumn{4}{|l|}{ Principle 5} \\
\hline Use & $41 \%$ & $36 \%$ & $45 \%$ \\
\hline Don't use & $41 \%$ & $36 \%$ & $45 \%$ \\
\hline Unsure & $18 \%$ & $29 \%$ & $9 \%$ \\
\hline \multicolumn{4}{|l|}{ Principle 6} \\
\hline Use & $59 \%$ & $45 \%$ & $73 \%$ \\
\hline Don't use & $9 \%$ & $18 \%$ & $0 \%$ \\
\hline Unsure & $32 \%$ & $36 \%$ & $30 \%$ \\
\hline
\end{tabular}

